\title{
Threatened Health in Women: A Qualitative Study on the Wives of War Veterans with Post-Traumatic Stress
}

\author{
Golbahar Akoondzadeh ${ }^{1}$, Abbas Ebadi ${ }^{2}$, Esmat Nouhi ${ }^{3} \&$ Hamid Hojjati ${ }^{4}$ \\ ${ }^{1}$ Nursing Research Center, Razi Faculty of Nursing and Midwifery, Kerman University of Medical Sciences, \\ kerman, Iran \\ ${ }^{2}$ Behavioral Sciences Research Center, School of Nursing, Baqiyatallah University of Medical Sciences, Tehran, \\ Iran \\ ${ }^{3}$ Nursing Research Center, Razi Faculty of Nursing and Midwifery, Kerman University of Medical Sciences, \\ kerman, Iran \\ ${ }^{4}$ Young Researchers and Elite Club, Aliabad Katoul Branch, Islamic Azad University, Aliabad Katoul, Iran \\ Correspondence: Abbas Ebadi, Behavioral Sciences Research Center, School of Nursing, Baqiyatallah \\ University of Medical Sciences, Tehran, Iran. E-mail: ebadi1347@yahoo.com
}

Received: September 21, 2016 Accepted: October 9, 2016 Online Published: January 5, 2017

doi:10.5539/gjhs.v9n3p176 URL: http://dx.doi.org/10.5539/gjhs.v9n3p176

\begin{abstract}
Introduction and Aim: Post-traumatic stress disorder causes distress and dysfunction in the life of the wives of veterans, which causes physical and mental health problems with the continuation of life. This study examined the life experiences of wives of war veterans with post-traumatic stress.
\end{abstract}

Materials \& Methods: This qualitative study using qualitative content analysis with the participation of 16 wives of war veterans with post-traumatic stress in Golestan province in Iran was conducted in 2015. Data was collected through semi-structured interviews and by purposive sampling and continued until data saturation. Data analysis was done continuously and simultaneously with data collection by content analysis method.

Findings: Four main categories and nine sub-categories including mental health (mental health problems and the memories), physical function (physical injuries and sleep disorders), captivity in life (humiliation, lack of independence in life), isolation (impairment in social interaction), dysfunction life (damage to the sons, the defect in family interactions) were the main findings of this study, which causes health threats.

Conclusion: Spouses of veterans have many problems in their daily lives and caregivers by understanding their needs and enhancing information systems, and social support can improve the function of their life.

Keywords: dysfunction, life experience, spouses, veterans with post-traumatic stress

\section{Introduction}

Post-traumatic stress disorder (PTSD) is a mental response to a severe stress (Yahyavi et al., 2015). War is one of the leading causes of this disorder (Vaccarino et al., 2013). Prevalence of the disease happens in 9-25 percent of war victims (SiratiNir et al., 2013). The condition is observed in the eighteenth \% of Iran-Iraq War veterans. According to statistics provided by the martyr and Veterans Foundation, 36354 war veterans are diagnosed with psychiatric, of which 1112 persons are at risk of mental disorders (Khdadadyan et al., 2012; Yahyavi et al., 2015). According to records contained in the file of veterans, more than $80 \%$ of them are suffering from post-traumatic stress disorder; they fall in a range of low to very severe (Bahrainis \& Borhani, 2003). It is known as one of the adverse effects of war on families and spouses of victims returning from the war (Renshaw et al., 2014). Spouses of veterans with PTSD psychological stress great experience (Erbes et al., 2012). Because the PTSD symptoms are passed from their husband to them (Yambo \& Johnson, 2014). Studies show that one in four spouses of veterans PTSD has symptoms (Kelly, 2010). Because often a family member due to frequent contact with an infected person throughout life, face a lot of emotional and neurological problems, which causes long-term impairment in family functioning and joint problems. Such as shame, guilt, distrust and adverse effects on interpersonal relationships and loss of intimacy in the household (Bravo-Mehmedbasic et al., 2010; Peraica et al., 
2014). It's continuing causes physical and psychological problems in the veterans' wives (Klaric et al., 2013; Wolf et al., 2013). Loneliness and anxiety about the future are other problems of veterans' wives (Tsai et al., 2012). Veterans' wives endure a lot of stress, such as the role and responsibilities of life, financial concerns, reduced social protection, increasing needs of children, and the lack of security in the family that causes fear and dysfunction of the household (Verdeli et al., 2011). War veterans' wives are psychological indirect victims of the war that have a lot of problems in social life, career and their family and attention to their sanitary, and mental health needs are considered as a necessity for the health care plan (Yambo \& Johnson, 2014). Since most studies on veterans' wives were done quantitative, some of these conditions cannot be assessed with a quantitative research and it's difficult to study mental characters with numerical tests. Investigating the life experiences by qualitative research is more effective than quantitative one (Caska \& Renshaw, 2011). This study was conducted to answer the question that the wives of war veterans with posttraumatic stress disorder, what experiences do they have in coping with the consequences of post-traumatic stress?

\section{Materials and Methods}

This qualitative study aimed to gain experiences from the wives of war veterans with post-traumatic and was conducted in 2015 by content analysis method (Conventional). Content analysis is a subjective interpretation of information themes, which can be detected through the regular classification process of topics or overt and covert patterns of text (Hsieh \& Shannon, 2005). Content analysis is synonymous with quantitative Analysis studies that this way information are concluded systematically and based on the objectives of the survey and the text of interview (Rudy et al., 2010). In this study, 16 women, according to inclusion criteria (married, has an excellent ability of communication and expression, the desire to participate in the study) regarding physical, mental and cognitive were able to answer questions and express their life experiences. Also, their husband should not be chemical, prisoners or amputated veterans of war and the post-traumatic stress disorder should be made by a psychiatrist based on the last criterion of DSM-V. The information in this study was selected based on purposive sampling in a range of age, education, occupation, place of residence, to comply with a maximum variability of participants. Research Environment was counseling centers of Martyr Foundation and veterans' home in the town of Golestan Province in Iran. To somehow become familiar with the study participants and the environment, researcher appeared in the situation, two weeks earlier. For ethical violations; the aim of this study was given to participants before the beginning of the interview. In addition to getting permission to record their voices and having speaking notes of the members, they were ensured that information is without indicating their name and in a case of no tendency, even during the interview, their information will be removed. The method interviews were conducted by the semi-structured method. The meeting began with general questions, but the more conversation was continued, the questioned would be more detailed and more specifics. The central research question was: "What is your experience of living with your spouse?" Explain yourself a day in the life", "What's different about your life with the lives of other people," how compatible you are with life's problems," it's possible to explain more about it or to give a clearer example.

The average duration of interviews was 65 minutes, according to the terms of the participants were varied between 45 to 100 minutes. During interviews data coding and categorizing were conducted simultaneously, which means researchers were faced with the same repetitive information, but to ensure two other interviews were carried out, but no new, different information were added to data. For data conventional content analysis process, the data analysis was based on Graneheim and Lundman method in 7 steps (Graneheim, 2004).

I: data and note-taking tips were arranged to analyze the content.

II: to familiarize with the data, the researcher has studied all texts several times, before encryption.

III: classes were extracted from data by inductive thinking that at this stage constant comparison between the data and obtained levels of each participant took place.

IV: encoding was done according to data and at the same time their stability and accuracy were controlled.

$\mathrm{V}$ : In this section, after encoding text and continuous control coding process, the necessary agreement between the researchers and participant about obtained codes was done.

VI: after the consensus of the members and scholars and facing the final code, information was provided to participants to control the accuracy of them, in the case of newer experiences of participants it can be added to the code.

VII: Finally, the conclusion was done from obtained codes, semantics, and last classes were derived from this 
information.

To ensure the efficacy and reliability of data obtained from this research contractor review standards, scientific accuracy were used such as Credibility, Confirmability and Transferability (Guba, 1981)

In this study, methods of validating were including the long-term involvement of research with the subject of study and information obtained from this research that controlling the accuracy of information was done by the help of participants and researchers. To reduce sampling error in the survey have tried to follow the maximum diversity regarding participants (age, education, occupation, disability percent, and duration of marriage). At the end Verifiability control was assessed by foreign observers, familiar with qualitative research results, this means that parts of the transcript of an interview with related codes and emerging classes were examined and approved by two supervisors, familiar with the qualitative research. For audit investigation, the researcher has the process of research accurately recorded and reported, to provide a possibility of a follow-up study.

\section{Findings}

From profound and rich descriptions of the participants, 690 codes were extracted. These codes, after several times review, were abstracted and classified by similarity and congruence. Analyzing and comparing their inner meaning were concluded of five main categories: mental health, physical function, bondage in life, social isolation and family dysfunction and nine sub-floors that together make up the concept of health threats (Table 1). Then in this section results for each parameter are presented separately to specify each class effect on veteran families.

Table 1. Classes and sub-classes Health, preparing post-traumatic stress in veteran familes

\begin{tabular}{|c|c|c|c|c|c|c|c|c|c|}
\hline \multicolumn{10}{|c|}{ Threatened Health } \\
\hline \multicolumn{2}{|c|}{ Mental health } & \multicolumn{2}{|c|}{ Physical function } & \multicolumn{2}{|l|}{ Bondage in life } & \multicolumn{2}{|c|}{ Social isolation } & \multicolumn{2}{|c|}{ Family dysfunction } \\
\hline $\begin{array}{l}\text { Mental } \\
\text { problems }\end{array}$ & $\begin{array}{l}\text { Bad } \\
\text { memories }\end{array}$ & $\begin{array}{l}\text { Physical } \\
\text { damage }\end{array}$ & $\begin{array}{l}\text { Sleep } \\
\text { disorder }\end{array}$ & $\begin{array}{l}\text { Lack of } \\
\text { independence } \\
\text { in life }\end{array}$ & Contempt & $\begin{array}{l}\text { Restrictions } \\
\text { on social } \\
\text { interaction }\end{array}$ & $\begin{array}{l}\text { Restrictions } \\
\text { on } \\
\text { connection } \\
\text { with family }\end{array}$ & $\begin{array}{l}\text { Damage } \\
\text { to } \\
\text { children }\end{array}$ & $\begin{array}{l}\text { Defects in } \\
\text { family } \\
\text { interactions }\end{array}$ \\
\hline
\end{tabular}

\subsection{Mental Health}

The participants' experiences show that spouses of veterans have mental mood swings that were reminding memories, and the problems cause anxiety and fear in them. In this study, mental health was obtained from two concepts of mental challenges and the reminding memories. Participants say in this regard:

"I do not have any attention to myself. My heart is so broken that I think it is cold and though as stone" (Participant No. 4). "I have bad memories that are always with me and always suffer me" (Participant No. 6). "This life was for me all suffering and fear. Always you think something bad is going to happen, and you fear that much that you don't understand living a life" (Participant No. 13). "The primary purpose of my life after this phenomena has been concentrated on family" (Participant No. 30). "These bad memories has been stuck in my mind, which cause disappointment and mental health problems on my son" (Participant No. 25)

\subsection{Physical Function}

The participants' experiences show that spouses of veterans have the physical function, caused by stress and pressure of life. This class includes two sub-classes; bodily harm and sleep disorder. "I don't sleep at all, and if I sleep, I will be woken up by a nightmare. I think my husband is going to attack me; I am tired of this type of living" (Participant No. 5). "I had that much pain that today I have heart problems, back pain, stomach pain and even medication do not calm them" (participant No. 14). "I have insomnia and suffer sleepless over the night" (participant No. 11).

\subsection{Bondage in Life}

The participants' experiences show that spouses of veterans, but the discomfort and embarrassment of this life and not having authority, are forced to tolerate this life, because of children and existing conditions. This class includes two sub-classes; lack of independence in life and contempt. Participants say in this regard: "when he is angry, nothing can stop him. He insults me, attacks me and pushes me out of the apartment. I am ashamed when 
he attacks me in front of the neighbors. When friends want to help me, he insults them either, and nobody can do anything" (Participant No. 4). "In these years I didn't have my life. I am always aware, not to make him angry and understand him. But I cannot go anywhere, and I don't have any right" (Participant No. 12). "My girls are young and want to go out; my husband is not in the mood and does not let us go out either. And if we want to go out always we should have an argument or contest and at the end, nothing is left except shame. We are not forced to having communication with anybody (participant No. 7).

\subsection{Social Isolation}

Members have stated because of their husband lack of interest in social contacts and fear of disgrace and incompatibility of their husband with family; they have been taken away from family and friends. This class includes two sub-classes; Restrictions on social interaction and Restrictions on connection with the household. Participants say in this regard: "We do not have any relationship with family and friends because my husband is not interested in such things and does not come anywhere and in the case of insisting and succeed in bringing him out, he would be tired very soon, and we should go back to home. We are alone" (Participant No. 2). "He is not in touch with anybody. He has no friend and is always not in the mood. When he is angry, we try not to be around him and not to make trouble. We do not even see my parents because of him" (Participant No. 3).

\subsection{Family Dysfunction}

Participants have shown their experience as a disorder in their interpersonal relation and with their husband as well as psychological problems in children. This class includes two sub-classes; Damage to children and Defects in family interactions.

"My oldest son is very nervous. He acts exactly like his father and when he is angry, he throws and punches everything. He doesn't have a patient for his wife. As well as my daughter that always has an argument with his husband" (Participant No. 9). "My husband does not eat or sleep with us. My children and I sleep in another room. There is no relation and love between us" (Participant No. 1). "There is no meaning of family in our life. I am always with my children. The role of one man and one father is always

\subsection{Threatened Health}

Mental health, Physical function, Bondage in life, Social isolation, Family dysfunction, mental problems, Bad memories, Physical damage, Sleep disorder, Lack of independence in life, Contempt Restrictions onsocialinteraction, Restrictions on connection with family Damage to children Defects in family interactions.

\subsection{Mental Health}

The participants' experiences show that spouses of veterans have mental mood swings that were reminding memories, and the problems cause anxiety and fear in them. In this study, mental health was obtained from two concepts of mental challenges and the reminding memories. Participants say in this regard:

"I do not have any attention to myself. My heart is so broken that I think it is cold and though as stone" (Participant No. 4). "I have bad memories that are always with me and always suffer me" (Participant No. 6). "This life was for me all suffering and fear. Always you think something bad is going to happen, and you fear that much that you don't understand living a life" (Participant No. 33).

\subsection{Physical Function}

The participants' experiences show that spouses of veterans have the physical function, caused by stress and pressure of life. This class includes two sub-classes; bodily harm and sleep disorder. "I don't sleep at all, and if I sleep, I will be woken up by the nightmare. I think my husband is going to attack me; I am tired of this type of living" (Participant No. 5). "I had that much pain that today I have heart problems, back pain, stomach pain and even medication do not calm them" (participant No. 32).

\subsection{Bondage in Life}

The participants' experiences show that spouses of veterans, but the discomfort and embarrassment of this life and not having authority, are forced to tolerate this life, because of children and existing conditions. This class includes two sub-classes; lack of independence in life and contempt. Participants say in this regard: "when he is angry, nothing can stop him. He insults me, attacks me and pushes me out of the apartment. I am ashamed when he attacks me in front of the neighbors. When friends want to help me, he insults them either, and nobody can do anything" (Participant No.35). "In these years I didn't have my life. I am always aware, not to make him angry and understand him. But I cannot go anywhere, and I don't have any right" (participant No. 22). "My girls are 
young and want to go out; my husband is not in the mood and does not let us go out either. And if we want to go out always we should have an argument or contest and at the end, nothing is left except shame. We are not forced to having communication with anybody (participant No. 9).

\subsection{Social Isolation}

Members have stated because of their husband lack of interest in social contacts and fear of disgrace and incompatibility of their husband with family; they have been taken away from family and friends. This class includes two sub-classes; Restrictions on social interaction and Restrictions in connection with the household. Participants say in this regard: "We do not have any relationship with family and friends because my husband is not interested in such things and does not come anywhere and in the case of insisting and succeed in bringing him out, he would be tired very soon, and we should go back to home. We are alone" (Participant No. 18). "He is not in touch with anybody. He has no friend and is always not in the mood. When he is angry, we try not to be around him and not to make trouble. We do not even see my parents because of him" (Participant No. 19).

\subsection{Family Dysfunction}

Participants have shown their experience as a disorder in their interpersonal relation and with their husband as well as psychological problems in children. This class includes two sub-classes; Damage to children and Defects in family interactions. "My oldest son is very nervous. He acts exactly like his father and when he is angry, he throws and punches everything. He doesn't have a patient for his wife. As well as my daughter that always has an argument with his husband" (Participant No. 20). "My husband does not eat or sleep with us. My children and I sleep in another room. There is no relation and love between us" (Participant No. 29). "There is no meaning of family in our life. I am always with my children. The role of one man and one father is always empty in our lives" (Participant No. 28). "My daughter has some problems in the wedding and finding a suitable person to marry with the particular situation of family" (Participant No. 26).

This qualitative study with regarding comprehensive factors intended to gain experiences from the families of war veterans with post-traumatic and was conducted to specify their effects on their life. Spouses of veterans suffer many mental and even physical problems due to their difficulties in their life. Their status can be improved by understanding their requirements, knowing their problems and social support.

\section{Discussion}

Post-traumatic stress disorder causes distress and dysfunction in the life of the wives of veterans, since the experience of living with a PTSD person, causes pressure and stress on their wives (Lambert et al., 2015). Study of previous studies showed that spouses of veterans have mental mood swings (Renshaw et al., 2011). Because the effects of war remain for years after it (Loncar et al., 2014). Reminding memories and the problems cause anxiety and fear in them (Monson et al., 2009). Even 15 years later, it can cause mental problems, and life dysfunction (Greene et al., 2014). Research conducted in Croatia showed that wives of PTSD victims suffer from sleep disorders (Franciskovic et al., 2007). Daily memories and these patient suffering cause nightmare and repetitive waking up, and this fear of horror create a mental problem or pressure (Rosen et al., 2013; Tamanna et al., 2014). The other problem of veterans' wives is the inability to control anger and irritability caused by physical damage (Monson et al., 2009). A headache, fatigue, chronic pains are physical problems of veterans' spouses, and these mental problems occur as Physical problems (Franciskovic et al., 2007). A study showed that there was a close relationship between increased violence and aggression PTSD victims and the feelings of shame and guilt in their women (Smith, 2011; Hundt \& Holohan, 2012). These women, with the motivation of supporting their husband and children, tolerate this life and have both role of father and mother in life responsibilities (SiratiNir et al., 2013). They are faced with lots of problems and stay in this situation because of their children (Mansfield et al., 2010; Runge et al., 2014). Tharp (2016) reviewed the Iraq and Afghanistan war veterans with post-traumatic stress disorder. It showed that irritability and aggression against the wife is one of the complications of this disorder which is often in the form of verbal and physical aggression can be seen.

Children are other victims of war because there would be no good relation between them and their father (Sherman et al., 2015). This disorder can be transfer to children (Zarh, 2015), which causes another anxiety in veterans' wives (Runge et al., 2014). Siegel and Davis (2013) investigated the mental problems and effects of Afghanistan and Iraq war on children and their mothers. They indicated that children in US military wars need health and mental health. Disruption and loss of intimacy in interpersonal relationships and marital interaction and correlation is another problem of life (Tsai et al., 2012). Couples often have communication problems and disruption in marital relations. In this life, love has no meaning, and there is an intense relationship (Monson et 
al., 2009). In these women, because of the sensibility of their husband in social relations, disorder, and limited social interactions have been observed (Vagharseyyedin, 2015). Care of chronic patient cause's impaired social relationships and feelings of loneliness, depression, and life dysfunction (Moradi et al., 2015). A qualitative study on veterans' wives stress disorder after the accident $t$ in Iran showed the negative impact on family structure and function are particularly spouses of veterans. Negative emotions, lack of social support and negative view are the problems of this study (Sirati Nir, 2013). In a similar study in Afghanistan, it was also shown social support and quality of life of veterans' wives than husbands were non-veterans (Nicole 2013). Similar studies in Australia revealed that most of the wives of veteran's mental health problems occur in the three decades after the war (O'Toole, 2010).

Negative symptoms of the disorder lead to increased stress and reduced family support this would undermine family relationships and social status (Hojjati et al., 2015; Ray \& Vanstone, 2009). Always because of fear of scandal or previous history of involvement with family, spouses of veterans prefer not to connect with others this is the while. The development of social interaction and social support can improve the quality of life (Duax et al., 2014; Voorhees \& Beckham, 2015). Vietnamese soldiers' wives who were suffering from post-traumatic stress disorder has symptoms of mental illness, which causes adverse effects. The investigation demonstrated that because of the nature of the disorder and irritability and aggressive behavior toward her husband, the intimacy and interpersonal relationships and life performance in these families are in trouble.

\section{Conclusion}

Regarding the limitations of this researches it can be noted that some participants, due to concern about disclosing secrets of life and problems, or loss of social support, they did not express their experiences convenient. In this research, we tried to create a cordial and friendly atmosphere during the interview to attract the trust of the participants and validate the research. Most studies in Iran were about troops and veterans, and less attention was given to review and investigate the status of veteran's spouses. Also, most similar studies were taken quantitatively. Therefore, this research was accompanied to examine the life of veteran's families and their problems on the life based on the nature of the qualitative approach. It concluded from the results that these families are under severe pressure, even after a long time of war. Hence, regarding Iran-Iraq war, with knowing theses families problems in the society and family, required mental health proposed. Spouses of veterans throughout life experienced the constant stress and psychological pressure, such as feelings of confusion, worry, despair, isolation and loneliness are. Due to children's future and cultural conditions of society, they are forced to endure conditions and stay in this life, which cause to malfunction of their life over the time.Understanding the needs of veteran's spouses, family support, providing consultancy services and information systems can help to improve the performance of life.

\section{Acknowledgements}

This article is part of the thesis PhD in Nursing with a code of ethics IR.KMU.REK 1394.141. Researchers express their gratitude to the support of authorities of Kerman University of Medical Sciences, officials of martyr Foundation of Golestan province in Iran and all participants of this research.

\section{Competing Interests Statement}

The authors declare that there is no conflict of interests regarding the publication of this paper.

\section{References}

Bahrainis, A., \& Borhani, H. (2003). Mental health in group of war veterans and their spouses in Qom. JOURNAL Pejouhesh, 27(4), 305-312. [In Persian]

Bravo-Mehmedbasic, A., Kucukalic, A., Kulenovic, A. D., \& Suljic, E. (2010). Impact of chronic Posttraumatic Stress Disorder on the Quality of life of war survivors. Psychiatr Danub, 22(3), 430-435.

Caska, C. M., \& Renshaw, K. D. (2011). Perceived burden in spouses of National Guard/Reserve service members deployed during Operations Enduring and Iraqi Freedom. J Anxiety Disord, 25(3), 346-351. http://dx.doi.org/ 10.1016/j.janxdis.2010.10.008

Duax, J. M., Bohnert, K. M., Rauch, S. A., \& Defever, A. M. (2014). Posttraumatic stress disorder symptoms, levels of social support, and emotional hiding in returning veterans. J Rehabil Res Dev, 51(4), 571-578. http://dx.doi.org/ 10.1682/jrrd.2012.12.0234

Erbes, C. R., Meis, L. A., Polusny, M. A., \& Arbisi, P. A. (2012). Psychiatric distress among spouses of National 
Guard soldiers prior to combat deployment. Ment Health Fam Med, 9(3), 161-169.

Franciskovic, T., Stevanovic, A., Jelusic, I., Roganovic, B., Klaric, M., \& Grkovic, J. (2007). Secondary traumatization of wives of war veterans with posttraumatic stress disorder. Croat Med J, 48(2), 177-184.

Graneheim, U. H., Lundman, B., \& 14- Hsieh HF, S. S. T. a. t. q. c. a. Q. H. R.-. (2004). Qualitative content analysis in nursing research: concepts, procedures and measures to achieve trustworthiness. Nurse Educ Today, 24(2), 105-112. http://dx.doi.org/10.1016/j.nedt.2003.10.001

Greene, T., Lahav, Y., Bronstein, I., \& Solomon, Z. (2014). The role of ex-POWs' PTSD symptoms and trajectories in wives' secondary traumatization. J Fam Psychol, 28(5), 666-674. http://dx.doi.org/ $10.1037 / \mathrm{a} 0037848$

Guba, E. G. (1981). ERIC/ECTJ Annual Review Paper: Criteria for Assessing the Trustworthiness of Naturalistic Inquiries. Educational Communication and Technology, 29(2), 75-91.

Hojjati, H., Ebadi, A., \& Zarea, K. (2015). Developing Erosion: The Experience of the Soldiers' Wives with PTST Arising from War. Indian Journal of Natural Sciences, 5(28), 3369-3370. [In Persian]

Hsieh, H. F., \& Shannon, S. E. (2005). Three approaches to qualitative content analysis. Qual Health Res, 15(9), 1277-1288. http://dx.doi.org/ 10.1177/1049732305276687

Hundt, N. E., \& Holohan, D. R. (2012). The role of shame in distinguishing perpetrators of intimate partner violence in U.S. veterans. J Trauma Stress, 25(2), 191-197. http://dx.doi.org/ 10.1002/jts.21688

Kelly, U. (2010). Intimate partner violence, physical health, posttraumatic stress disorder, depression, and quality of life in latinas. West J Emerg Med, 11(3), 247-251.

Khdadadyan, Z., Sirati Nir, M., Khamse, F., \& Ebadi, A. (2012). Comparison the effect of training of conflict resolution and management of emotional intelligence on Life satisfaction's spouses of war veterans affected psychological disorders. IJWPH, 4(3), 52-61. [In Persian]

Klaric, M., Kvesic, A., Mandic, V., Petrov, B., \& Franciskovic, T. (2013). Secondary traumatisation and systemic traumatic stress. Psychiatr Danub, 25(Suppl 1), 29-36.

Lambert, J. E., Hasbun, A., Engh, R., \& Holzer, J. (2015). Veteran PTSS and spouse relationship quality: The importance of dyadic coping. Psychol Trauma, 7(5), 493-499. http://dx.doi.org/ 10.1037/tra0000036

Loncar, M., Plasc, I. D., Bunjevac, T., Hrabac, P., Jaksic, N., Kozina, S., \& Marcinko, D. (2014). Predicting symptom clusters of posttraumatic stress disorder (PTSD) in Croatian war veterans: the role of socio-demographics, war experiences and subjective quality of life. Psychiatr Danub, 26(3), 231-238.

Mansfield, A. J., Williams, J., Hourani, L. L., \& Babeu, L. A. (2010). Measurement invariance of posttraumatic stress disorder symptoms among U.S. military personnel. J Trauma Stress, 23(1), 91-99. http://dx.doi.org/ $10.1002 /$ jts. 20492

Monson, C. M., Taft, C. T., \& Fredman, S. J. (2009). Military-related PTSD and intimate relationships: from description to theory-driven research and intervention development. Clin Psychol Rev, 29(8), 707-714. http://dx.doi.org/ 10.1016/j.cpr.2009.09.002

Moradi, A., Ebrahimzadeh, M. H., \& Soroush, M. R. (2015). Quality of life of caregiver spouses of veterans with bilateral lower extremity amputations. Trauma Mon, 20(1), e21891. http://dx.doi.org/ 10.5812/traumamon.21891

Peraica, T., Vidovic, A., Petrovic, Z. K., \& Kozaric-Kovacic, D. (2014). Quality of life of Croatian veterans' wives and veterans with posttraumatic stress disorder. Health Qual Life Outcomes, 12, 136. http://dx.doi.org/ 10.1186/s12955-014-0136-x

Plumb, T. R., Peachey, J. T., \& Zelman, D. C. (2014). Sleep disturbance is common among servicemembers and veterans of Operations Enduring Freedom and Iraqi Freedom. PsycholServ, 11(2), 209-219. http://dx.doi.org10.1037/a0034958

Ray, S. L., \& Vanstone, M. (2009). The impact of PTSD on veterans' family relationships: An interpretative phenomenological inquiry. International Journal of Nursing Studies, 46(6), 838. http://dx.doi.org/ 10.1016/j.ijnurstu.2009.01.002

Renshaw, K. D., Allen, E. S., Carter, S. P., Markman, H. J., \& Stanley, S. M. (2014). Partners' attributions for 
service members' symptoms of combat-related posttraumatic stress disorder. Behav Ther, 45(2), 187-198. http://dx.doi.org/ 10.1016/j.beth.2013.10.005

Renshaw, K. D., Allen, E. S., Rhoades, G. K., Blais, R. K., Markman, H. J., \& Stanley, S. M. (2011). Distress in spouses of service members with symptoms of combat-related PTSD: secondary traumatic stress or general psychological distress? J Fam Psychol, 25(4), 461-469. http://dx.doi.org/10.1037/a0023994

Rosen, C., Adler, E., \& Tiet, Q. (2013). Presenting concerns of veterans entering treatment for posttraumatic stress disorder. J Trauma Stress, 26(5), 640-643. http://dx.doi.org/10.1002/jts.21841.

Rosen, C., Adler, E., \& Tiet, Q. (2013). Presenting concerns of veterans entering treatment for posttraumatic stress disorder. J Trauma Stress, 26(5), 640-643. http://dx.doi.org/10.1002/jts.21841

Rudy, R. M., Popova, L., \& Linz, D. G. (2010). The Context of Current Content Analysis of Gender Roles: An Introduction to a Special Issue. Sex Roles, 62(11-12), $705-720$. http://dx.doi.org/10.1007/s11199-010-9807-1

Runge, C. E., Waller, M., MacKenzie, A., \& McGuire, A. C. (2014). Spouses of military members' experiences and insights: qualitative analysis of responses to an open-ended question in a survey of health and wellbeing. PLoS One, 9(12), e114755. http://dx.doi.org/ 10.1371/journal.pone.0114755

Sherman, M. D., Larsen, J., Straits-Troster, K., Erbes, C., \& Tassey, J. (2015). Veteran-child communication about parental PTSD: A mixed methods pilot study. $J$ Fam Psychol, 29(4), 595-603. http://dx.doi.org/10.1037/fam0000124

Siegel, B. S., \& Davis, B. E. (2013). Health and mental health needs of children in US military families. Pediatrics, 131(6), e2002-15. http://dx.doi.org/10.1542/peds.2013-0940

Sirati Nir, M., Ebadi, A., Fallahi Khoshknab, M., \& Tavallae, A. (2013). Spiritual experiences of war veterans who suffer from combat-related post-traumatic stress disorder: A qualitative study. J Relig Health, 52(3), 719-729 http://dx.doi.org/10.1007/s10943-012-9629-2

Smith, S., S., M., \& W., C. C. (2011). Awareness of posttraumatic stress disorder in veterans: A female spouse/intimate partner perspective. Mil Med., 176(7), 743-751.

Tamanna, S., Parker, J. D., Lyons, J., \& Ullah, M. I. (2014). The effect of continuous positive air pressure (CPAP) on nightmares in patients with posttraumatic stress disorder (PTSD) and obstructive sleep apnea (OSA). $J$ Clin Sleep Med, 10(6), 631-636. http://dx.doi.org/10.5664/jcsm.3786

Tamanna, S., Parker, J. D., Lyons, J., \& Ullah, M. I. (2014). The effect of continuous positive air pressure (CPAP) on nightmares in patients with posttraumatic stress disorder (PTSD) and obstructive sleep apnea (OSA). $J$ Clin Sleep Med, 10(6), 631-636. http://dx.doi.org/10.5664/jcsm.3786

Tsai, J., Harpaz-Rotem, I., Pietrzak, R. H., \& Southwick, S. M. (2012). The role of coping, resilience, and social support in mediating the relation between PTSD and social functioning in veterans returning from Iraq and Afghanistan. Psychiatry, 75(2), 135-149. doi: 10.1521

Vaccarino, V., Goldberg, J., Rooks, C., Shah, A. J., Veledar, E., Faber, T. L., \& Bremner, J. D. (2013). Post-traumatic stress disorder and incidence of coronary heart disease: A twin study. J Am Coll Cardiol, 62(11), 970-978. http://dx.doi.org/10.1016/j.jacc.2013.04.085

Vagharseyyedin, S. A. (2015). Experiences of wives of Iranian war veterans with posttraumatic stress disorder regarding social relationships. Public Health Nurs, 32(2), 122-131. http://dx.doi.org/10.1111/phn.12118

Van Voorhees, E. E., \& Beckham, J. C. (2015). Advancements in treating intimate partner violence in veterans. $J$ Clin Psychiatry, 76(6), e826-827. http://dx.doi.org/10.4088/JCP.14com09556

Verdeli, H., Baily, C., Vousoura, E., Belser, A., Singla, D., \& Manos, G. (2011). The case for treating depression in military spouses. J. Fam Psychol, 25(4), 488-496. http://dx.doi.org/10.1037/a0024525

Wolf, E. J., Harrington, K. M., Reardon, A. F., Castillo, D., Taft, C. T., \& Miller, M. W. (2013). A dyadic analysis of the influence of trauma exposure and posttraumatic stress disorder severity on intimate partner aggression. J Trauma Stress, 26(3), 329-337. http://dx.doi.org/ 10.1002/jts.21805

Yahyavi, S. T., Zarghami, M., Naghshvar, F., \& Danesh, A. (2015). Relationship of cortisol, norepinephrine, and epinephrine levels with war-induced posttraumatic stress disorder in fathers and their offspring. Rev Bras Psiquiatr, 37(2), 93-98. http://dx.doi.org/ 10.1590/1516-4446-2014-1414 
Yambo, T., \& Johnson, M. (2014). An integrative review of the mental health of partners of veterans with combat-related posttraumatic stress disorder. $J$ Am Psychiatr Nurses Assoc, 20(1), 31-41. http://dx.doi.org/10.1177/1078390313516998.

\section{Copyrights}

Copyright for this article is retained by the author(s), with first publication rights granted to the journal.

This is an open-access article distributed under the terms and conditions of the Creative Commons Attribution license (http://creativecommons.org/licenses/by/4.0/). 